\title{
Socio-economic analysis in REACH restriction dossiers for chemicals management: A critical review
}

\author{
Silke Gabbert $\mathbb{D}$, Isabel Hilber
}

Received: 6 May 2019/Revised: 16 October 2019/Accepted: 22 October 2019/Published online: 5 December 2019

\begin{abstract}
This paper offers a critical review of socioeconomic analysis (SEA) in Registration, Evaluation, Authorisation and Restriction of Chemicals (REACH) restriction dossiers. We examine the conceptual setup of SEA and identify the methods used for impact assessment. Moreover, we analyse the outcomes of quantitative impact assessment across restriction dossiers and substance groups. We find that impact assessment has largely focused on economic and health impacts. Environmental, social, wider economic and distributional impacts have either been evaluated qualitatively or not at all. While this can be explained by the specific scope of the proposed restriction or by lacking data, we also observe a lack of approaches for environmental and health impact assessment. This underlines the need to develop integrated methods that transform information about chemical effects and risks into impacts and, ultimately, into benefits and damages. Furthermore, to strengthen the function of SEA as decision-support tool in REACH restriction procedures, a comparative SEA of at least two alternative restriction options should be the default.
\end{abstract}

Keywords Impact assessment $\cdot$ REACH $\cdot$ Regulation · Restriction of chemicals · Risk management .

Socio-economic analysis

\section{INTRODUCTION}

The ambition of the European chemicals' legislation REACH (Registration, Evaluation, Authorisation and

Electronic supplementary material The online version of this article (https://doi.org/10.1007/s13280-019-01285-9) contains supplementary material, which is available to authorized users.
Restriction of Chemicals) is to ensure "a high level of protection of human health and the environment, including promoting alternative methods for assessment of hazards of substances, while enhancing competitiveness and innovation" (European Commission 2006). There is wide agreement that REACH has significantly improved information about the properties and the risks of chemicals in use, or intended to be placed on the market in amounts larger than 1 tonne/year (Hansen et al. 2007; Getzner and Schulz-Zak 2018). Furthermore, reversing the 'burden of proof', i.e. shifting the responsibility to provide relevant information about chemical properties, exposures and their (safe) use(s) from regulatory authorities to chemical producers, manufacturers and downstream users, has been considered a paradigm-change in European chemicals risk management (Hansen et al. 2007; Béal and Deschamps 2016). While a comprehensive, quantitative assessment of the short- and long-term impacts of REACH at the European level has not become available as yet, several studies have presented estimates of the expected environmental, cleanup, public and occupational health costs saved (cf. Reihlen and Lüskow 2007 for a survey).

REACH adopts two complementary regulatory instruments, (i) authorisation, i.e. the formal approval to continue one or multiple uses of a substance for a defined time period, and (ii) restriction, i.e. the enforcement of measures to reduce or eliminate the risks from producing, manufacturing and marketing a substance. An authorisation process is initiated by companies, i.e. producers, manufacturers and downstream users, who can apply for authorisation of specific uses of 'Substances of Very High Concern" (SVHC, European Chemicals Agency (ECHA) 2019a and European Commission (EC) 2006, Title VII, see also Klika 2015), pure or in a mixture. SVHCs are chemicals which are classified as one of the following 
(i) carcinogenic, mutagenic or toxic for reproduction, (ii) persistent, bioaccumulative or toxic (PBT) or very persistent and very bioaccumulative ( $\mathrm{vPvB})$, (iii) endocrine disrupters, or substances that (iv) give "rise to an equivalent level of concern" (EC 2006, Article 57). A restriction process, by contrast, can either be initiated by regulatory authorities of EU member states or by the ECHA on request of the EC. Restrictions apply to any substance, to substances in a mixture or in a product. Restricted substances can, but do not have to be SVHC (ECHA 2019b). For both authorisation and restriction procedures, the EC takes the final decision, taking into account the written opinions of the ECHA Risk Assessment Committee (RAC) and the ECHA Socio-economic Assessment Committee (SEAC). Whereas a decision on authorisation is binding for the authorisation holder only, a decision on restriction applies to all companies (i.e. producers, manufacturers, downstream users, retailers) of EU member states. Regulatory authorities of EU member states are responsible for its enforcement (ECHA 2007, 2019b).

The focus of this paper is on REACH restrictions. Most commonly, a restriction process is initiated when an EU member state, or ECHA on request of the EC, starts preparing an Annex XV restriction dossier (ECHA 2019e). Based on the written opinions of RAC and SEAC, the applicant prepares a final background document of the proposed restriction. A restriction dossier includes detailed information about (i) the suggested restriction of a substance's use, (ii) its hazards, risks, and existing alternatives (e.g. the use of substitutes or alternative technologies), (iii) the need to adopt regulatory measures at an EU-wide level, and (iv) the expected positive and negative impacts of the proposed restriction or other possible risk management options (RMOs). Finally, a restriction dossier reports (v) results of stakeholder consultations regarding possible impacts of the proposed restriction.

For assessing expected impacts, dossier submitters can add a socio-economic analysis (SEA). Generally, an SEA is "an approach to analysing all relevant impacts (i.e. both positive and negative changes) of one scenario against another", and serves as "a decision-support tool to evaluate the costs and benefits an action will create for society by comparing what will happen if this action is implemented as compared to the situation where the action is not implemented" (ECHA 2008, 2011). In the REACH restriction process, an SEA can be used in order to motivate the need for community-wide action, to justify the appropriateness of a restriction proposal, or to assess the expected benefits and costs for different societal actors (manufacturers, importers, consumers, etc.) under the proposed restriction (ECHA 2008). Though an SEA is not mandatory for REACH restrictions, it is recommended to be included into a restriction proposal in order to assess the proportionality, i.e. the societal acceptability, of the proposed restriction (ECHA 2008). Consequently, most restriction dossiers contain an SEA (ECHA 2019d), which underlines its perceived strategic relevance for decisionmaking. To facilitate SEA in REACH restriction procedures, the ECHA has published guidance documents outlining the different components of an SEA and possible methodological approaches (ECHA 2008, 2010). So far, however, there has been little insight on how SEAs have been applied in REACH restriction procedures.

Conducting an SEA is a time- and resource-consuming task. An obvious and relevant question is, therefore, how applicants have accomplished SEAs in REACH restriction dossiers, and what outcomes have become available from the assessments. This paper offers a systematic and structured evaluation of SEAs in $24 \mathrm{REACH}$ restriction dossiers. Specifically, we explore (i) the purpose(s) of an SEA, (ii) the types of impacts assessed, (iii) the methodological approaches used for impact assessment and aggregation, and (iv) the main quantitative outcomes of an SEA. Particular attention is given to comparing results between substances classified as SVHC and non-SVHC. Under the REACH legislation, SVHCs are usually aimed to be phased-out unless the EC has granted a formal authorisation for specific uses of the substance. A restriction applying to all uses and EU member states can be more efficient and easier to implement than a ban on specific uses only. However, if the substance has a widespread use and cannot straightforwardly be substituted by an alternative substance or technology, EU member states may have a strong incentive to restrict an SVHC. Based on our findings regarding (i)-(iv), we discuss (v) the contribution of an SEA for decision-making on restrictions.

Closest to our study is a recent report published by the ECHA, which compares aggregate cost and benefit information retrieved from 18 adopted restriction proposals (ECHA 2016). The report documents cost and benefit estimates that are presented in the final background documents for the chosen restriction. Our paper goes beyond this analysis by addressing a broader sample of restriction dossiers and by providing an in-depth analysis of the methodological approaches adopted in and the outcomes of SEAs.

The remainder of the paper is organised as follows: The "Materials and Methods" section informs about the materials and methods used. Specifically, we discuss the approach adopted for the comparative evaluation of SEA based on defined plausibility criteria. Following to this, we discuss the practical implementation of SEA in REACH restriction dossiers. The "Discussion" section concludes and points to implications from our analysis for decisionmaking on restrictions under REACH. 


\section{MATERIALS AND METHODS}

\section{Restriction dossiers included in the evaluation}

So far, restrictions have been adopted for 70 chemicals (ECHA 2019d). Of these, 45 substances had already been restricted under the previous legislation, EU Directive 76/769/EEC (EU 1976). These restrictions were formally converted to REACH restrictions without passing through the regular procedure of submitting a REACH Annex XV restriction dossier (ECHA 2019d). For 25 substances, restriction procedures were conducted according to REACH guidelines (ECHA 2007). For 24 of these, (draft) opinions from the ECHA Risk Assessment and the Socioeconomic Assessment Committee (RAC and SEAC) have been adopted until December 2018 and were included in our analysis.

Detailed documentation about the different stages of the restriction process per substance (i.e. restriction proposal, draft and final RAC and SEAC opinions including minority positions, submitters' responses to RAC/SEAC opinions, final background document, adopted restriction) is available on the ECHA website (https://www.echa.europa.eu/ substances-restricted-under-reach). For the comparative evaluation of SEA, we used the final background documents, i.e. the restriction proposals amended by comments based on the opinions of the RAC and the SEAC (ECHA 2019d). Table S1 in the Electronic Supplementary Material (ESM) provides basic information about the dossiers included in the analysis, i.e. the substance names and their CAS numbers, the date of dossier submission, and the name of the submitting authority. The table also indicates whether a substance belongs to the group of SVHC according to REACH criteria. Furthermore, the table presents the baseline scenario for SEA, the RMOs specified by the dossier submitter and, where available, the regulatory decision adopted by the EC.

\section{The scope of SEA in REACH restriction dossiers}

A REACH Annex XV restriction dossier usually starts with formulating a 'proposed restriction', i.e. a control measure to reduce or eliminate the risks arising from the use of a substance on its own or in articles. This can be a control measure prohibiting manufacture or the use of a substance in articles, their placement on the market, occupational safety measures, a market removal of products containing a substance, the implementation of new technology, or the establishment of upper concentration limits for a substance's use in articles. Besides the proposed restriction, the dossier submitter should identify possible alternative RMOs, including measures under other existing Community legislation (e.g. the European Water
Framework Directive, EC 2000), existing sector- and usespecific legislation, or voluntary risk management measures to be adopted by industry. The dossier submitter must motivate why the proposed restriction, or any of the alternative RMOs, is the most appropriate control measure on a Community-wide basis. This is done by assessing an RMO's effectiveness, practicality, and monitorability (ECHA 2008). These base criteria, in turn, consist of different sub-criteria as shown in Fig. 1. 'Effectiveness' addresses the expected risk reduction capacity of a restriction measure, i.e. its potential to decrease exposure to a level that is considered acceptable and that allows for an adequate control of the remaining risks. Furthermore, the expected costs of the restriction as well as expected risks of possible alternative substances or technologies need be assessed. Moreover, applicants need to document the proposed timeline for reducing exposure to an acceptable level. A restriction is considered 'proportional' if it targets the intended reduction of risks in an efficient and cost-effective way, and if restriction effects are well-balanced with the effort and time required by actors for implementing and enforcing it. In addition, it needs to be assessed whether the restriction is compatible with existing legal frameworks (ECHA 2008). Besides being effective, a restriction should be implementable, enforceable and manageable with reasonable effort. Finally, in order to ensure a successful implementation of a proposed restriction, the authority needs to outline how the (intermediate) results of the restriction, e.g. the expected reduction of production levels, the levels of use(s), or expected reduced emission and exposure levels, can be monitored over time.

Although it is not obligatory, most restriction dossiers include an SEA. Following the ECHA guidance document on SEA for restriction processes (ECHA 2008), an SEA can have several, complementary functions as shown in Table 1.

An SEA assesses the expected positive and negative impacts of the proposed restriction, and of one or several alternative RMOs. Such an assessment usually starts with determining a 'baseline scenario' (Table S1 in the ESM), which determines the societal risk that is expected to occur in the absence of control measures. The baseline scenario is either a business-as-usual scenario assuming an on-going use of the substance under defined market conditions, or an alternative RMO. The baseline scenario can also include forward looking projections about, for instance, future price levels and demand, expected policy changes or technical innovations facilitating substitution. Restriction dossiers did usually not distinguish between alternative baseline specifications.

The (expected) impacts arising from a particular RMO are assessed against the baseline scenario. Following 


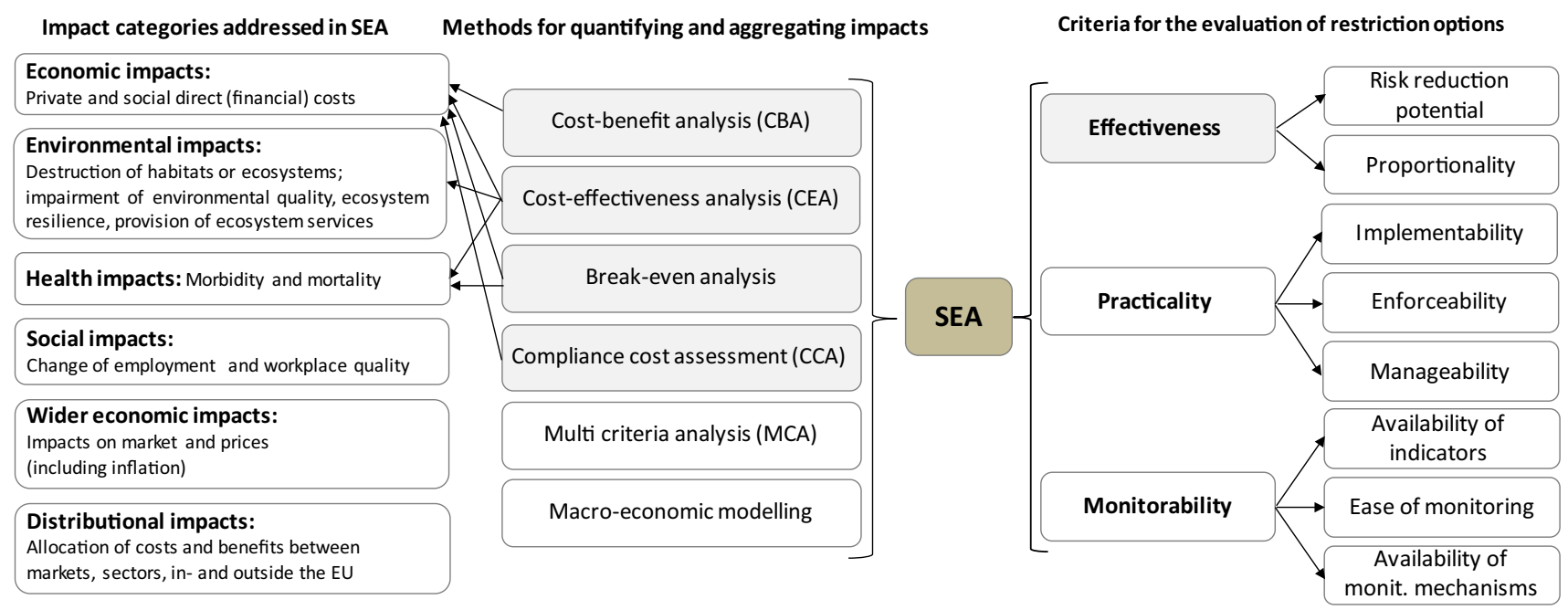

Fig. 1 Impact categories addressed in SEA for REACH restriction procedures, methods suggested for quantifying and aggregating impacts in SEA, methods used in SEA (grey-shaded), criteria for evaluating restriction options, and evaluation criteria that were informed by SEA (greyshaded). Source: Adapted from ECHA (2008). Arrows indicate the methods that were applied for assessing an impact category

Table 1 Scope of SEA in REACH restriction dossiers

\begin{tabular}{|c|c|}
\hline Purpose & Explanation \\
\hline $\begin{array}{l}\text { Justification that community-wide } \\
\text { action is required }\end{array}$ & $\begin{array}{l}\text { Assessment whether expected } \\
\text { positive and negative impacts } \\
\text { from the use of a substance are } \\
\text { improved/worsened with a } \\
\text { community-wide action }\end{array}$ \\
\hline $\begin{array}{l}\text { Assessment whether the proposed } \\
\text { restriction is the most } \\
\text { appropriate community-wide } \\
\text { action }\end{array}$ & $\begin{array}{l}\text { Comparative assessment of } \\
\text { different RMOs regarding their } \\
\text { effectiveness, practicality and } \\
\text { monitorability }\end{array}$ \\
\hline $\begin{array}{l}\text { Refinement of the restriction } \\
\text { proposal }\end{array}$ & $\begin{array}{l}\text { Assessment whether a } \\
\text { modification of the proposed } \\
\text { restriction will increase } \\
\text { effectiveness, practicality and } \\
\text { monitorability of the RMO }\end{array}$ \\
\hline $\begin{array}{l}\text { Assessment of the proposed } \\
\text { restriction }\end{array}$ & $\begin{array}{l}\text { Assessment of benefits and costs } \\
\text { under the proposed restriction }\end{array}$ \\
\hline
\end{tabular}

Source ECHA (2008)

ECHA (2008), impacts comprise environmental and human health impacts, economic impacts (e.g. net costs of the RMO for producers, manufacturers, importers, downstream users and the society), social impacts (i.e. impacts that do not belong to health and environmental impacts, e.g. change of working conditions) and wider economic impacts (i.e. impacts on trade, competition and economic development). In addition, impacts on the distribution of social costs and benefits within and outside the EU (distributional impacts) should be analysed (Fig. 1).

To conclude about a restriction option's effectiveness, practicality and monitorability, the different types of impacts need to be quantified and compared against each other. For this purpose, the REACH Guidance on SEA (ECHA 2008) for restrictions suggests different tools (Fig. 1). Cost-benefit analysis (CBA), compliance cost assessment (CCA) and macro-economic modelling require to express impacts in monetary terms. Cost-effectiveness analysis (CEA) and break-even analysis, by contrast, allow some impact categories to be expressed in their natural units, e.g. the number of health incidences observed. CCA captures particularly direct (financial) costs occurring to sectors that are affected by a restriction, which can include cost components belonging to different impact categories (e.g. economic impacts, wider economic and distributional impacts, ECHA 2008). Results of a CCA can also feed in a CBA or in a CEA. A multi-criteria analysis (MCA) is used when robust monetary values do not exist for all impact categories and, thus, quantitative and qualitative impact information have to be considered, weighed and aggregated. Macro-economic models analyse how impacts of a restriction will affect the economy as a whole, for example, through a change of price and income levels or employment. Since they require a large amount of input information, macro-economic models have been considered to be of minor relevance for SEA in REACH restriction procedures (ECHA 2008).

\section{Plausibility criteria for a comparative evaluation of SEA in REACH restriction dossiers}

For the comparative evaluation of SEA in REACH restriction dossiers, we define a set of plausibility criteria, which characterise the conceptual setup, the methodological approach, and the outcomes of SEA. The criteria are listed in Table 2. 
Table 2 Plausibility criteria for the evaluation of SEA in $24 \mathrm{REACH}$ restriction dossiers

\begin{tabular}{|c|c|}
\hline Criteria & Explanation, example(s) \\
\hline \multicolumn{2}{|l|}{ Conceptual setup of SEA } \\
\hline Baseline scenario & Business-as-usual situation \\
\hline Scope of an SEA & $\begin{array}{l}\text { Purpose for which SEA was performed } \\
\text { (Table 1) }\end{array}$ \\
\hline RMOs considered & $\begin{array}{l}\text { Proposed restriction and alternative } \\
\text { RMOs }\end{array}$ \\
\hline \multicolumn{2}{|c|}{ Methodological approach to impact assessment in SEA } \\
\hline Impact categories addressed & $\begin{array}{l}\text { Human health impacts, environmental } \\
\text { impacts, economic impacts, social } \\
\text { impacts, wider economic impacts, } \\
\text { distributional impacts (Fig. 1) }\end{array}$ \\
\hline Type of IA & E.g. qualitative/quantitative assessment \\
\hline $\begin{array}{l}\text { Method used for impact } \\
\text { aggregation/comparison }\end{array}$ & $\begin{array}{l}\text { E.g. cost-effectiveness analysis, cost- } \\
\text { benefit analysis, compliance cost } \\
\text { assessment (Fig. 1) }\end{array}$ \\
\hline $\begin{array}{l}\text { Discounting of monetised } \\
\text { impacts }\end{array}$ & Type of discounting method used \\
\hline Uncertainty analysis & $\begin{array}{l}\text { Types of uncertainties addressed and } \\
\text { method used for uncertainty analysis } \\
\text { (qualitative, deterministic, } \\
\text { probabilistic) }\end{array}$ \\
\hline \multicolumn{2}{|l|}{ SEA outcomes } \\
\hline $\begin{array}{r}\text { Main results of a } \\
\text { quantitative IA }\end{array}$ & $\begin{array}{l}\text { Results of quantitative impact } \\
\text { assessment }\end{array}$ \\
\hline $\begin{array}{l}\text { Adopted restriction } \\
\text { decisions }\end{array}$ & $\begin{array}{l}\text { Comparison of initially proposed, } \\
\text { selected and adopted restriction }\end{array}$ \\
\hline
\end{tabular}

IA impact assessment

\section{Evaluation of quantitative SEA results}

An SEA evaluates different types of impacts arising from the restriction options suggested, and facilitates the selection of the RMO that is ultimately preferred by the dossier submitter. Key quantitative outcomes of an SEA are estimates of a restriction's expected costs and benefits. Costs of a restriction comprise different components, e.g. compliance costs, substitution costs, testing costs, or costs for training and implementation. Benefits usually consist of avoided health incidents or health damage costs, but can also include increased workplace safety, and incentives for technology development and adoption. In addition, the expected risk reduction capacity of a restriction option, expressed as, for example, the expected emission reduction or the number of avoided health incidences per period (e.g. per year), can be used as a quantitative, non-monetary estimate of benefits. Since a restriction of a substance can have long-term impacts on different societal actors and the environment, cost and benefit estimates presented in SEA can stretch over several years or even decades (Table S3 in the ESM).

Clearly, the properties and uses of the substances addressed in the 24 restriction dossiers differ. Consequently, estimates of the risk reduction capacity, costs and benefits under different restriction options vary widely across dossiers. Using R version 3.4 .3 (2017-11-30), we compared the estimates provided for risk reduction capacity, costs and benefits between substances. For our comparison, we distinguished substances classified as SVHC from non-SVHC by a Student's $t$ test. Furthermore, we fitted a linear regression into the data of expected costs and benefits, using the following model:

$\log 10(y)=a+b * \log 10(x)+\varepsilon$,

where $y$ denotes the benefit estimates, $x$ the cost estimates, $a$ is the intercept, $b$ the slope in the linear regression and $\varepsilon$ is the error term. Statistically significant influence was denoted at a $p$ value $\leq 0.05$. Prior to the statistical analysis ( $t$ tests and regression analysis), the variables denoting costs and benefits were log transformed and the arc$\sin (\operatorname{sqrt}(x))$ from the risk reduction capacity values was calculated in order to achieve a normal/t-distribution.

\section{RESULTS: PRACTICAL IMPLEMENTATION OF SEA IN REACH RESTRICTION DOSSIERS}

\section{Conceptual setup of SEA}

An overview of the methodological approaches for assessing impacts in SEA, and of the main outcomes of SEA for RMOs that were selected by the dossier submitter, is presented in Table 3. Information on SEA was retrieved from final background documents available at ECHA (2019d). Table S1 in the ESM offers further information about the baseline scenarios, the restriction options identified by the dossier submitter, and, where available, the regulatory decision adopted. Restriction options that the dossier submitter considered inappropriate from the outset (e.g. risk management measures under other European legislations) were not included in the analysis. Depending on the use of the chemical, the societal risk under the baseline scenario was expressed in terms of the amount of consumer articles placed on the market, the number of humans or animals affected, the future production, export or import volume of a substance, the use volume of a substance in consumer articles, or current and future emissions.

In addition to the initially proposed restriction, REACH restriction dossiers often identified one or more alternative RMOs. However, in several dossiers (e.g. Pb in jewellery, NP/NPE, PFOA, BPA, Pb-PVC, phthalates (2017), $\mathrm{NH}_{4}$, 


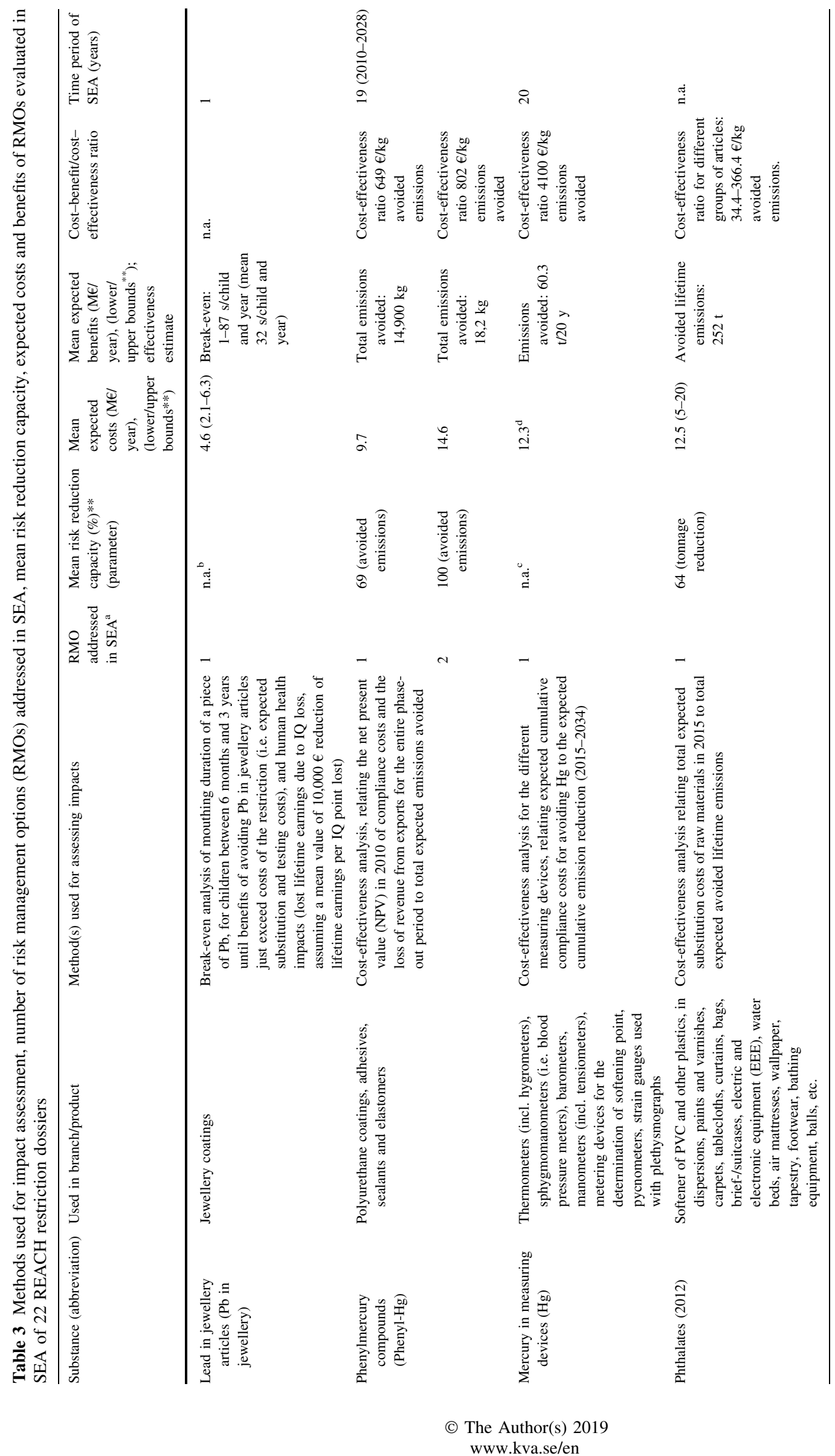




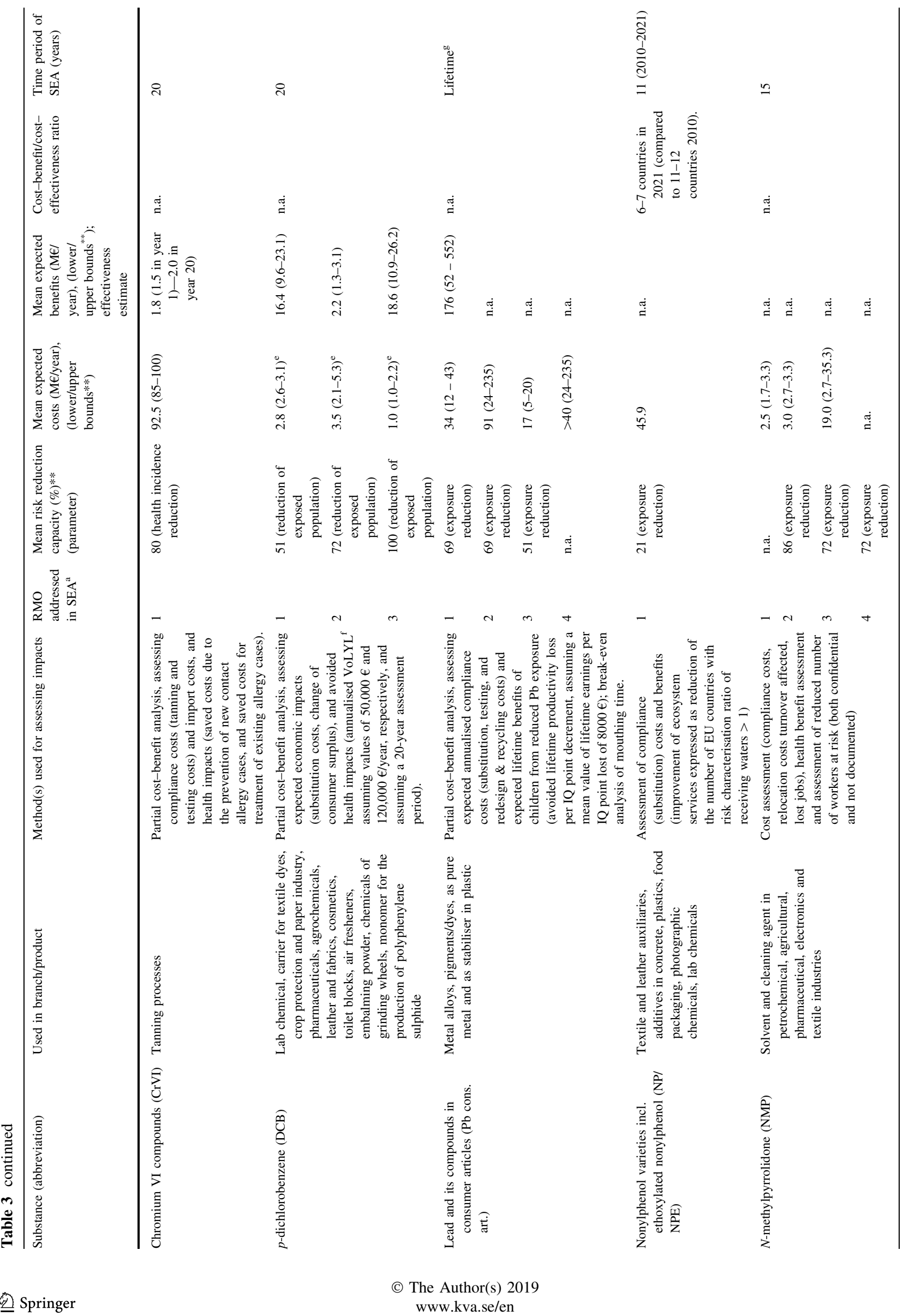




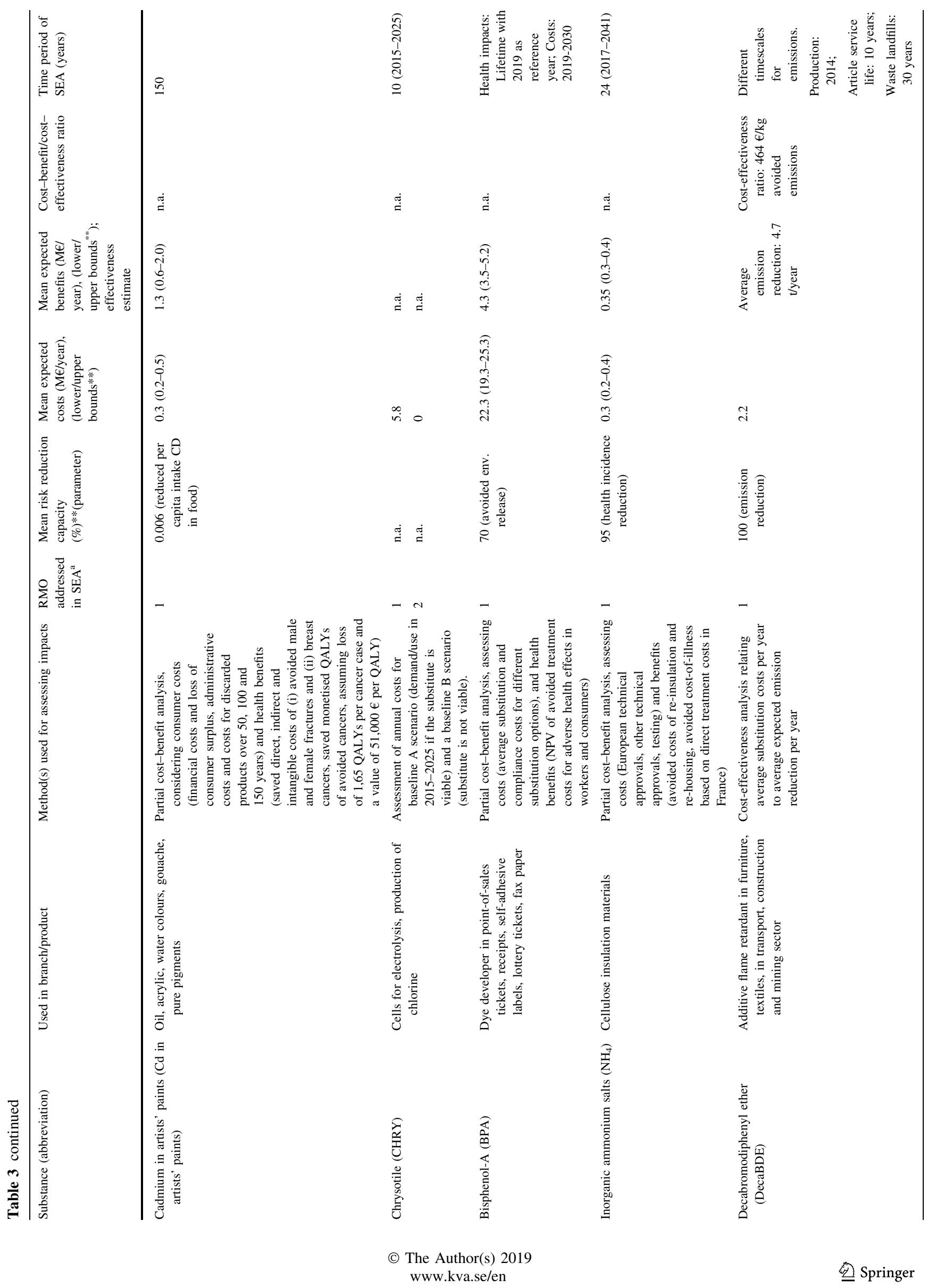




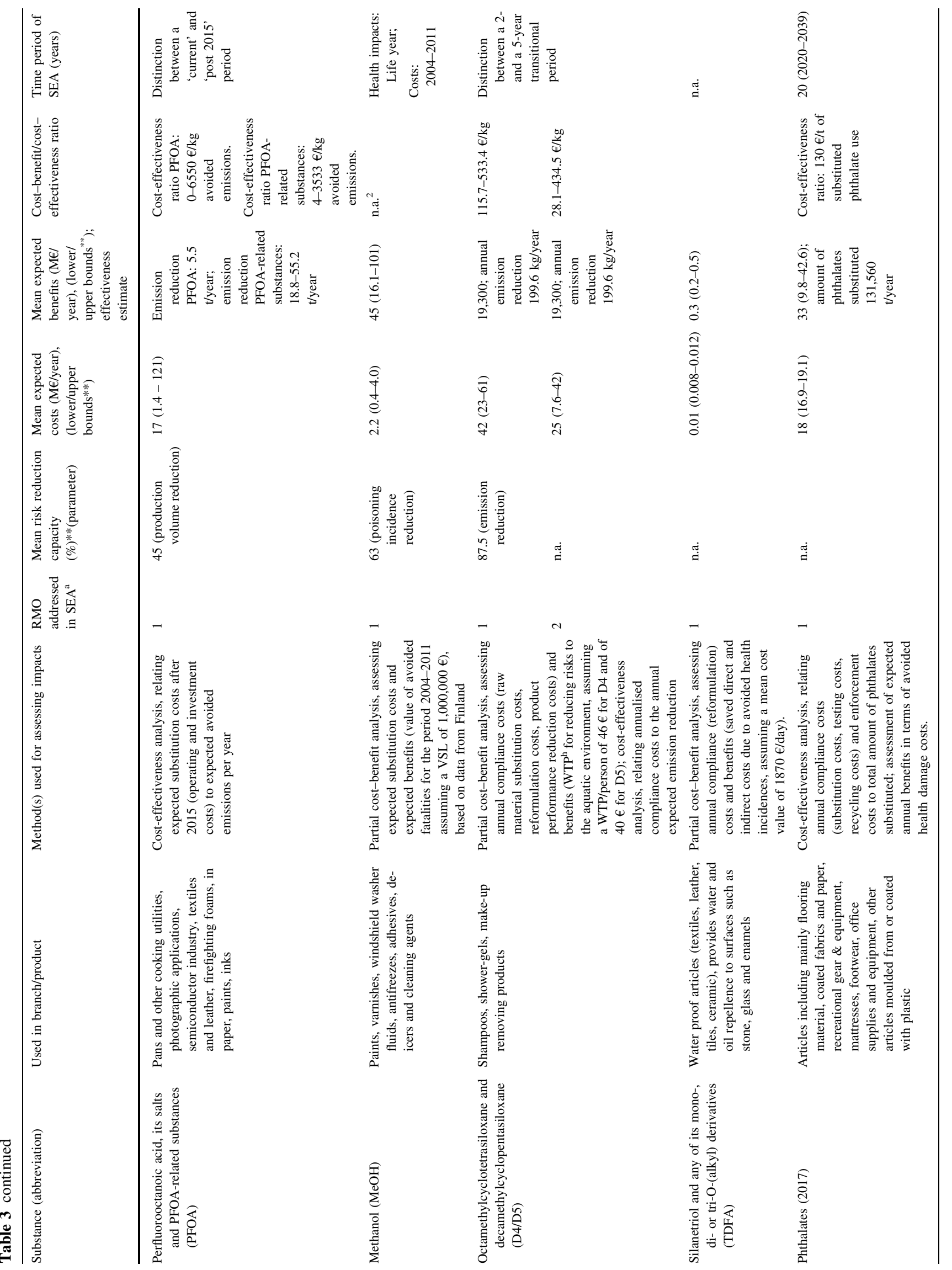




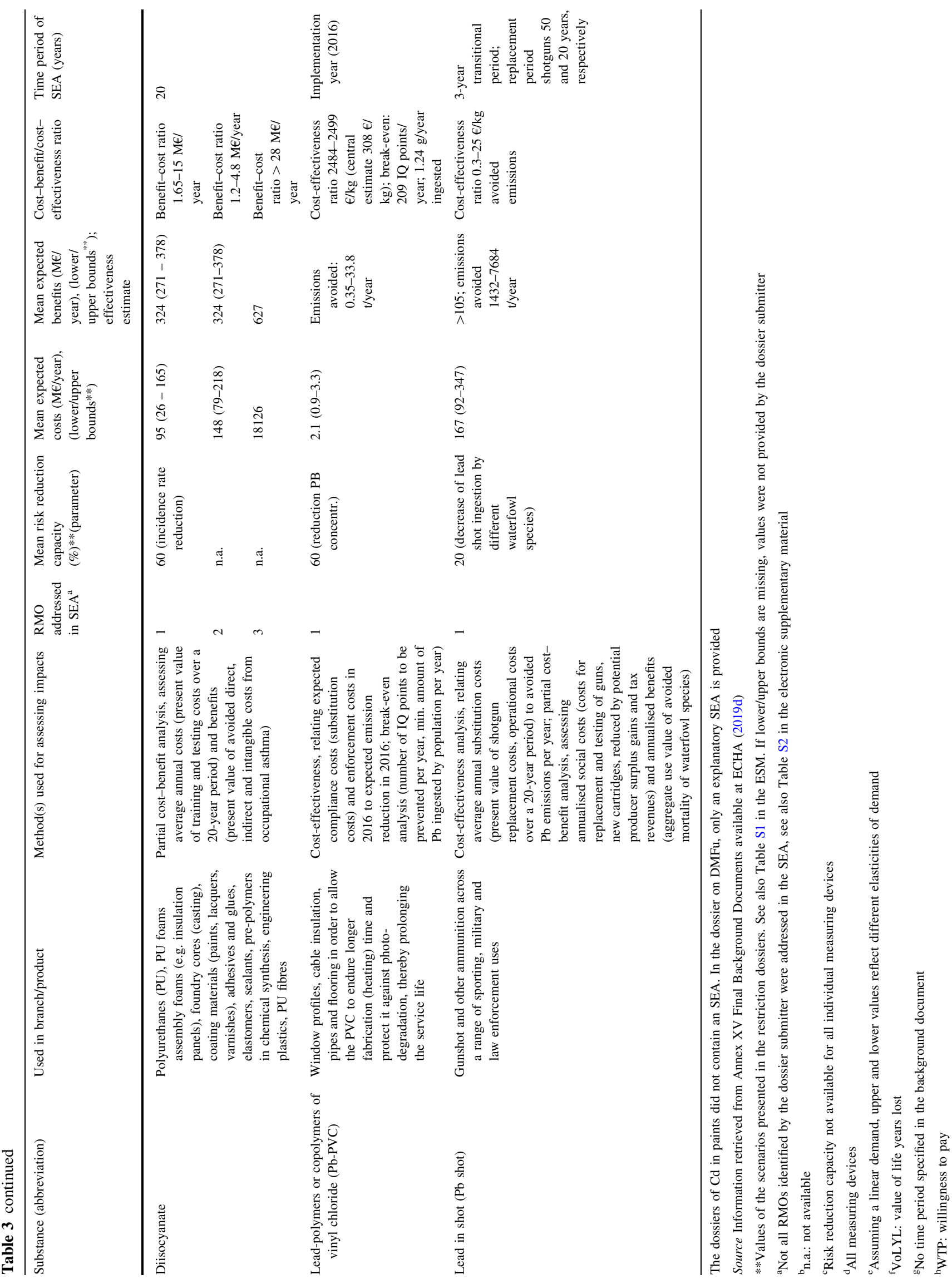


$\mathrm{Cd}$ in artists' paints), only the preferred (and thus preselected) RMO was further evaluated with an SEA (purpose 4 in Table 2, see also Table S1 in the ESM). ${ }^{1}$ Two restriction dossiers (e.g. DMFu, $\mathrm{MeOH}$ ) proposed only one restriction measure, which then by default became the preferred option. ${ }^{2}$ Restriction dossiers for Phenyl-Hg, $\mathrm{DCB}, \mathrm{NMP}, \mathrm{Pb}$ in consumer articles, diisocyanate, chrysotile, D4/D5 and decaBDE provided a comparative evaluation of the proposed restriction for selected alternative RMOs (Table 3, column 4), which is more comprehensive and, thus, more time and resource consuming than conducting an SEA for individual restriction options only. From the perspective of a dossier submitter, a comparative evaluation seems reasonable if expected social gains and losses are high. Though our analysis did not reveal a clear relationship between the number of restriction options assessed and the quantitative outcomes of SEA (Fig. 2), we find that dossiers providing a comparative evaluation of two, three, or more RMOs document large differences between the different restriction options for at least one outcome parameter (Table 3, columns 5-7).

The risk reduction capacity of an RMO was expressed using estimates of the expected emission reduction, avoided health/poisoning incidences, human or environmental exposure, tonnage reduction, or the reduced concentration of a substance (Table 3, column 5). Due to uncertain or lacking data, impacts were often assessed for different scenarios assuming, for instance, different time spans, alternative economic growth rates, or different estimates of the number of people affected. For RMOs with a quantitative impact assessment we present the mean values, and the lower and upper bounds of cost and benefit estimates (Table 3, columns 6 and 7).

\section{Methodological approach to impact assessment in SEA}

For assessing impacts of an RMO, the dossier submitters used partial CBA, CEA, CCA and break-even analysis. MCA and macro-economic modelling were not applied in SEA. Generally, impacts can be assessed in a qualitative (descriptive) or in a quantitative manner. Furthermore,

\footnotetext{
${ }^{1}$ See Hilber and Gabbert (2019) for a detailed analysis of the RMO selection process.

2 Recent restriction dossiers (e.g. phthalates (2017), diisocyanates (2017), and Pb-PVC (2017)) have adopted a new format. Specifically, the organisation of the reports changed from a topic-related approach (with separate sections for the presentation of the proposed restriction (A), hazard and exposure assessment (B), alternative substances information (C), the justification for action on a Union-wide basis (D) and the justification why the proposed restriction is the most appropriate (E), SEA of the proposed restriction $(\mathrm{F})$ ) to a processoriented approach where the evaluation of RMOs including SEA has been consolidated into one section "Impact assessment".
}

quantitative impact assessments can either be expressed in monetary or non-monetary terms.

Figure 3 illustrates the type of impact assessments for 23 of the 24 REACH restriction dossiers considered. The restriction dossier for $\mathrm{Cd}$ was excluded because it did not contain an SEA. For each dossier, we indicate whether a certain impact category was assessed or not, and what types of approaches to impact assessment were applied (explanatory, quantitative but non-monetary, monetary assessment).

Overall, we observe that the routines for impact assessment vary considerably across restriction dossiers. In 16 of 23 dossiers, only selected impacts were assessed, i.e. one or more impact categories were not addressed. Economic impacts were quantified and monetised in 21 dossiers. In case of human health impacts, 10 of 23 dossiers included monetary assessments of human health impacts. Specifically, the analyses provided estimates of expected (avoided) health damage costs given the adoption of the selected restriction measure (Table 3, column 3).

Economic impacts were predominantly assessed as financial costs, in particular direct compliance or implementation costs (Table 3, column 3). In addition, dossier submitters presented, where possible and appropriate, information about indirect compliance costs such as price changes due to a change of product quality. Compliance costs were often used as approximation of economic impacts. Only few dossiers (Phenyl-Hg, DCB, Cd in artist paints, phthalates 2017, $\mathrm{Pb}$ in gunshots) adopted an approach to assessing economic impacts that includes, besides financial costs, opportunity cost components (monetary estimates of foregone opportunities for resource use (OECD 2002), including enforcement costs and expected changes of consumer or producer surplus).

Compared to economic impacts, quantified health and environmental impacts capture the (avoided) external costs and, thus, the benefits of a restriction option in comparison to the baseline scenario. Two dossiers ( $\mathrm{Pb}$ in shot, NP/ NPE) offered a quantitative assessment of (avoided) environmental impacts, i.e. NP/NPE and Pb in shot (Table 3). In the latter dossier environmental impacts were assessed as avoided opportunity costs of water birds saved by the restriction. The restriction dossier for NP/NPE adopted a simplified ecosystem services approach, using the change of the number of EU member states with a risk characterisation ratio (RCR) in freshwater of $<1$ as a proxy for an overall improvement of ecosystem services. A qualitative (explanatory) assessment of environmental impacts was presented in the dossiers TDFA, phthalates 2017, CrIV, BPA, Pb-PVC, D4/D5, Phenyl-Hg, decaBDE, $\mathrm{MeOH}$, and DMFu. Several dossiers (diisocyanates, DCB, $\mathrm{NH}_{4}, \mathrm{Cd}$ in artist paints, NMP, $\mathrm{Hg}, \mathrm{Pb}, \mathrm{CHRY}, \mathrm{Pb}$ in jewellery) did not provide an environmental impact 


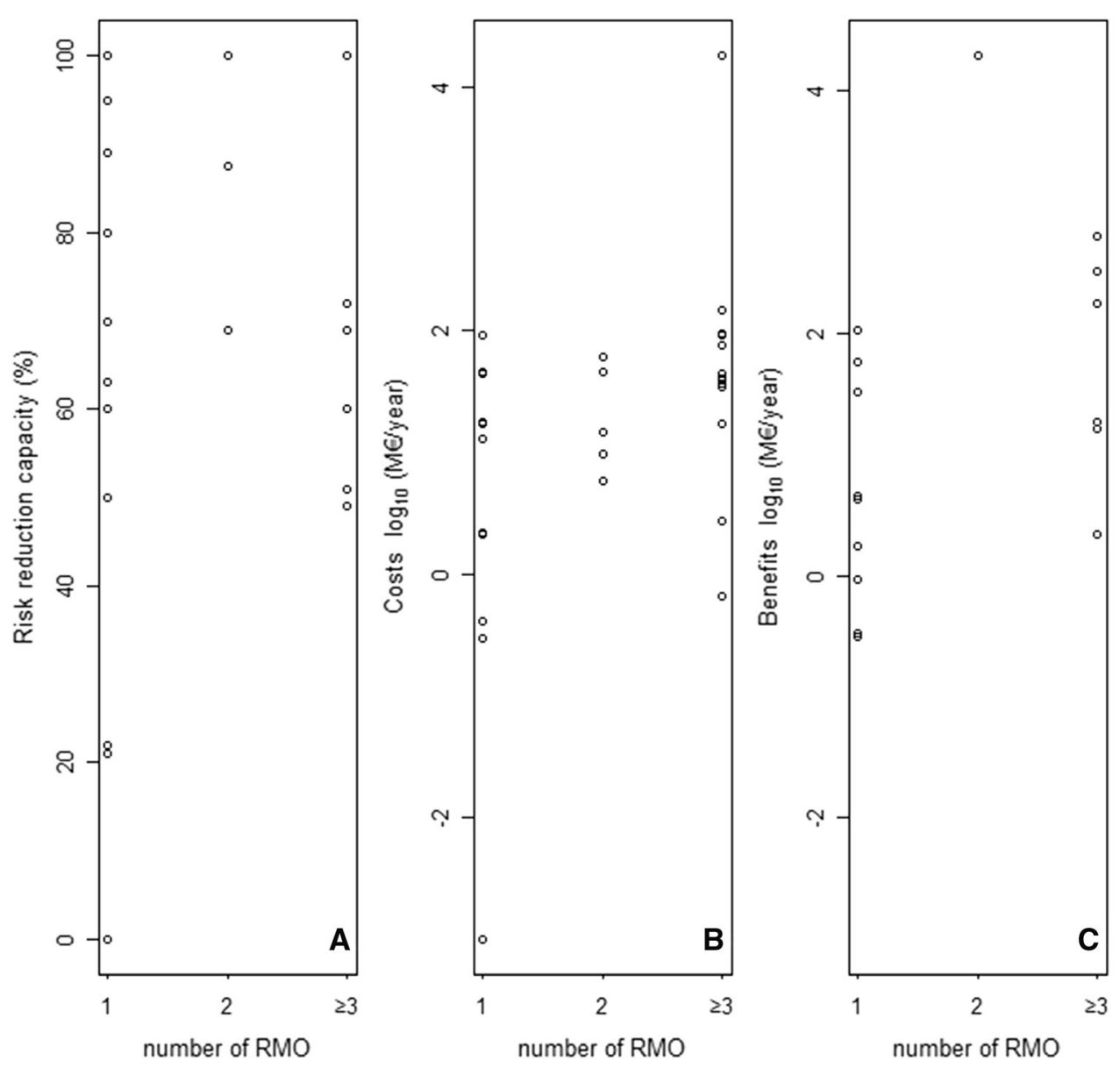

Fig. 2 Mean risk reduction capacity (a), cost (b) and benefit (c) estimates of 20 REACH restriction dossiers, grouped according to the number of restriction options (1,2 and $\geq 3$ RMOs) included in the SEA. To make different approaches for assessing restriction options' risk reduction capacity comparable with each other, the risk reduction capacity was expressed as \% improvement compared to the baseline. Source Data provided in Table 3

assessment because it was considered beyond the scope of the restriction, or due to a lack of information (Fig. 3). Similarly, social, wider economic and distributional impacts were predominantly evaluated qualitatively, and remained unassessed in three dossiers.

For assessing health impacts, different approaches were used. Several dossiers (Cr IV, D4/D5, TDFA, Diisocyanate, Phthalates 2012) quantified health impacts as avoided health damage costs, which were assessed as saved direct costs (cost-of-illness, health treatment costs) and indirect costs (avoided productivity loss, saved losses of lifetime earnings). Where health impacts could not straightforwardly be expressed as (saved) costs, impact parameters related to morbidity and mortality such as the number of fatalities, or utility-based measures such as Quality Adjusted Life years (QALY) or Value of a Life Year (VOLY) estimates and IQ points lost were monetised using available information on, for example, the willingness to pay (WTP) for avoiding a health incidence, or money values per QALY/VOLY ( $\mathrm{Pb}$ in jewellery, DCB, $\mathrm{Cd}$ in artists' paints, $\mathrm{Pb}$ in consumer products, $\mathrm{MeOH}$ ).

Where health and environmental impacts were neither monetised nor quantified, estimates of the expected reduction of emissions were used as proxy of avoided impacts and, thus, the benefits of a restriction option. Note that the change of emissions also served as a proxy for a restriction option's risk reduction capacity, being a key component for evaluating the effectiveness of a restriction option (Fig. 1).

Obviously, impact assessment in an SEA is forward looking. Expected costs and benefits usually stretch over a time period, and can occur in different periods. To make estimates of benefits and costs of a restriction option comparable in an intertemporal setting they need to be discounted to their present values (Heal 2007). In the economics literature, different discounting approaches have been discussed, of which exponential discounting (using a constant discount rate) and hyperbolic discounting 

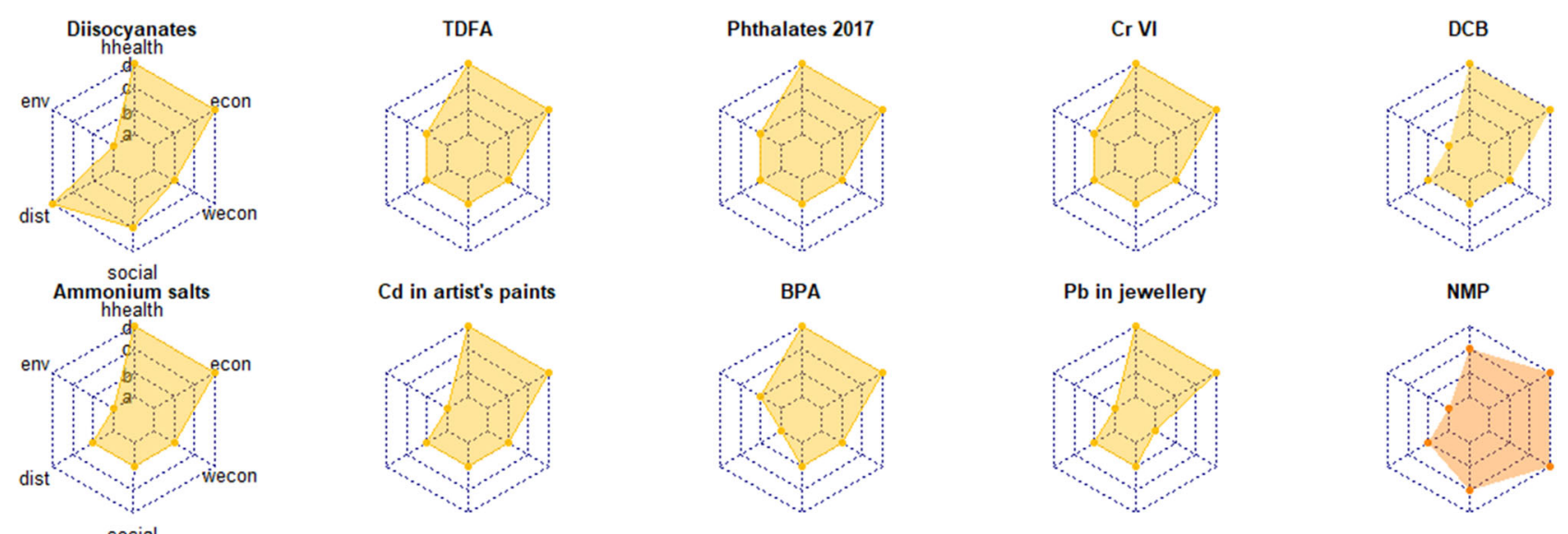

Cd in artist's paints
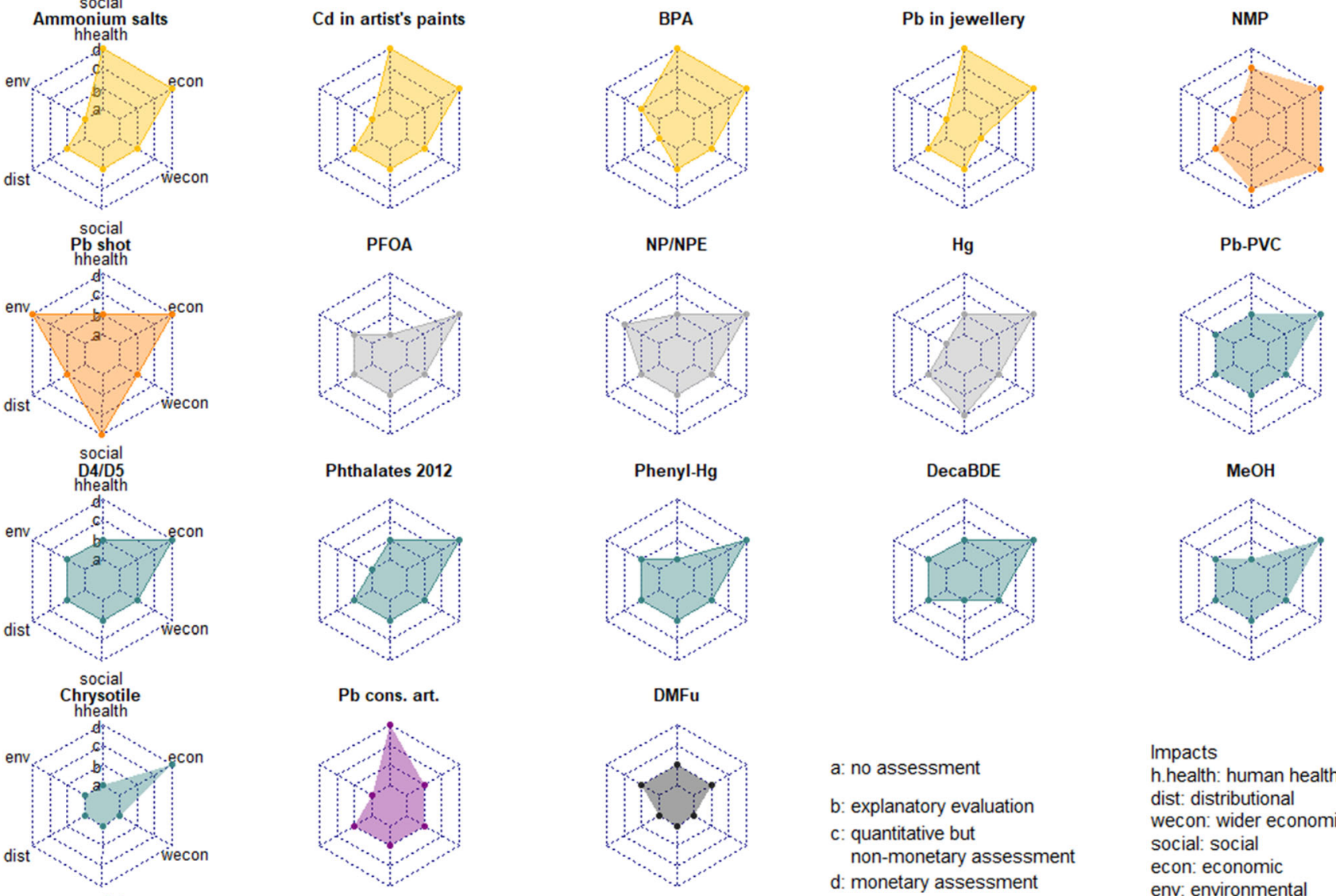

Impacts

h.health: human health dist: distributional wecon: wider economic social: social econ: economic env: environmental

Fig. 3 Approaches to impact assessment in SEA of 23 REACH restriction dossiers. Radar charts of restriction dossiers with a similar methodological approach to impact assessment have the same colour. Source Annex XV Final Background Documents available at ECHA (2019d)

(using a declining discount rate) are most prominent (Samuelson 1937; Osborne 2016). The REACH Guidance for SEA in restrictions (ECHA 2008) offers an overview of discount rates applied at the EU level (e.g. in the Impact Assessment Guidelines of the EC, European Commission 2019) and at the national level of EU Member States. Furthermore, a sensitivity analysis using different discount rates is recommended if the time span of expected costs and benefits to occur exceeds 30 years. Following the recommendations in the impact assessment guidelines of the EC (2019), the majority of restriction dossiers adopted exponential discounting using a standard discount rate of
4\% for both cost and benefit estimates (Table S3 in the ESM). Two dossiers (Cd in artists' paints and BPA) offered a critical discussion of the impacts of discounting on costs and benefit assessments. These dossiers addressed restrictions on substances with a clear inter-generational spread of costs and benefits (i.e. $>30$ years). For the assessment of avoided health damage costs, a higher discount rate (e.g. 3.5 or $4 \%$ ) was applied for early years, whereas a lower discount rate $(2 \%)$ was used for late years of the assumed time period. Eight dossiers (Phthalates 2012, Cd in paints, DFMu, decaBDE, PFOA, MeOH, D4/D5, Pb shot) did not apply or discuss discounting, although they addressed 
substances with a clear long-term impact profile. Though there are arguments for using (very) low positive or even negative discount rates if impacts are expected to occur far in the future (Weitzman 1998; Fleurbaey and Zuber 2013), the lack of discounting was often not motivated in the dossiers (decaBDE, PFOA, D4/D5).

Given the complex hazard and use profiles of substances addressed in REACH restriction processes, impact estimates provided in restriction dossiers are subject to different types of uncertainties. Our analysis revealed that parameter uncertainty (referring to the value of a parameter used in SEA, e.g. emissions, production/import/export volumes, cost parameters, the number of people exposed, the price elasticity of demand, the implementation period), model uncertainty (referring to the setup of an assessment, e.g. the shape of the market demand curve) and legal uncertainty (e.g. implementation of authorisations) were most frequently discussed (Table S3 in the ESM). The REACH Guidance document (ECHA 2008) suggests addressing uncertainties by applying sensitivity analysis, scenario analysis, or expert judgement. Of the 24 dossiers analysed, 20 applied a quantitative deterministic uncertainty analysis, being either sensitivity analysis or scenario analysis. None of the dossiers applied probabilistic methods (e.g. Monte Carlo Analysis) for uncertainty analysis.

\section{SEA outcomes}

In most restriction dossiers, the preferred control measure was equivalent to the proposed restriction option (Table S1 in the ESM). Exemptions are the dossiers on chrysotile and PFOA, its salts and PFOA-related substances. For chrysotile, a restriction had already been in place before REACH entered into force, however, Member States had granted exemptions until 2025. In the restriction dossier, the submitter suggested a continued use of chrysotile as preferred RMO, based on a binding agreement with users to fully substitute chrysotile until 2025. In case of PFOA, the dossier submitter preferred a full ban to a ban with possible derogations (ECHA 2019d, Table S1 in the ESM). Furthermore, dossier submitters did not always base the selection of the preferred RMO on the outcomes of SEA. For instance, although RMO 2 showed a superior costeffectiveness ratio than RMO 1 in the D4/D5 dossier (Table 3, column 8), the latter was selected as it was considered proportionate with the cost-effectiveness ratios estimated in other dossiers (Table S1 in the ESM, ECHA 2019d).

As illustrated in Fig. 3, not all impact categories addressed in an SEA were assessed quantitatively. Where economic, and health and/or environmental impacts were quantified and monetised, dossier submitters conducted a partial CBA ( $\mathrm{Pb}$ cons, $\mathrm{Cd}$ in artist paints, $\mathrm{DCB}, \mathrm{BPA}, \mathrm{Cr}$
IV, MeOH, D4/D5, Diisocyanate, TDFA, Pb in shot, Table 3). Cost and benefit values were not always combined to a net present value (NPV) estimate, but documented separately. Where health and/or environmental impacts could be quantified but not monetised, CEA was applied, relating the expected costs of a restriction option to expected annual or lifetime emissions avoided (Phenyl$\mathrm{Hg}, \mathrm{Hg}$ in measuring devices, phthalates (2012 and 2017), decaBDE, PFOA, Pb-PVC, D4/D5, Pb in shot). Two dossiers $(\mathrm{Pb}$ in jewellery and $\mathrm{Pb}-\mathrm{PVC})$ also offered a breakeven analysis for assessing health impacts. In some cases (NP/NPE, NMP, chrysotile), the dossier submitter considered health or environmental impacts to be beyond the scope of the proposed restriction or to be of only marginal relevance and, thus, gave focus to economic impacts using a CCA.

Figure 4 compares key quantitative outcomes of an SEA, i.e. the restriction option's risk reduction capacity (panel A), costs (panel B) and benefits (panel C) between substances classified as SVHC and non-SVHC. We find that estimates of the risk reduction capacity, the expected costs and the expected benefits of an RMO are usually higher for dossiers addressing SVHC. For the expected benefits of a proposed RMO this effect is significant ( $p$ value 0.032 ).

This may be explained by considering that SVHC are substances which, according to their properties, are likely to cause long-term impacts to the environment or to human health. These impacts can easily outweigh the costs of a restriction that occur in a limited time period. In addition, the uncertainty regarding the size and the occurrence of impacts is often high (Daston et al. 2003; Brouwer et al. 2016). This may cause benefit assessments, being the social gains of a restriction and expressed in terms of the risk reduction capacity, or as avoided health and environmental impacts, to be overstated in comparison to cost estimates, denoting predominantly the financial costs of firms.

Finally, using linear regression, the benefits of a restriction were related to costs reported in 13 restriction dossiers (Fig. 5). We find a significant and positive linear relationship between expected $\log _{10}$ costs and $\log _{10}$ benefits (see Table S2 in the ESM, $p$ value of 0.0026). This suggests that dossier submitters are willing to accept higher costs for restrictions if substances that are expected to reveal relatively higher benefits.

For the majority of dossiers, the EC adopted the restriction that was identified as preferred option by the dossier submitter, however, following the comments of the RAC and/or SEAC, modifications were added in several cases (Table $\mathrm{S} 1$ in the ESM). In few cases ( $\mathrm{Pb}$ in jewellery, NMP, PFOA), the decision adopted by the EC deviated from the RMO preferred by the dossier submitted. 

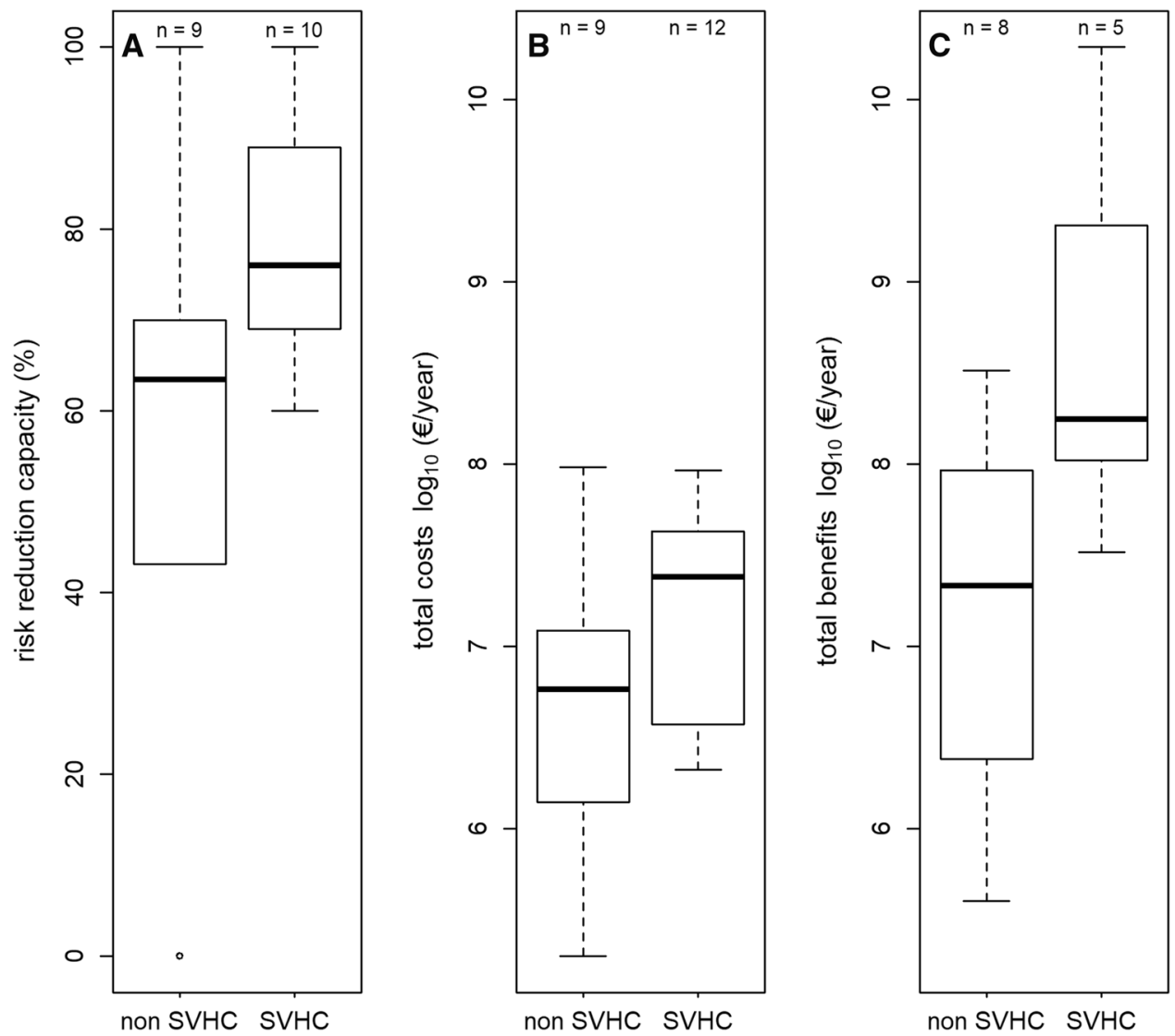

Fig. 4 Risk reduction capacity (A), costs (B) and benefits (C) of substances classified as Substances of Very High Concern (SVHC) and nonSVHC. Sample sizes differ between panels due to lacking quantitative estimates for the different parameters. In each panel the subgroup size is indicated above every boxplot. The upper and lower ends of the box represent the 25th and 75th percentiles, the horizontal line in the box the median, and the upper and lower whiskers are the 10th and 90th percentiles, respectively. The dot in panel A is an outlier. Source ECHA (2019d), own calculations

The restriction dossiers of two substances, phthalates 2012 and Cd in artists' paints, were rejected by the EC because the necessary conditions provided by REACH Art. 68 were considered not to be fulfilled. For TDFA, Diisocyanates, $\mathrm{Pb}-\mathrm{PVC}$ and $\mathrm{Pb}$ in shot opinions from $\mathrm{RAC}$ and SEAC have been adopted, however, final decisions of the EC are still pending (Table S1 in the ESM, ECHA 2019d).

\section{DISCUSSION}

This paper is, to the best of our knowledge, the first offering a systematic and critical review of the methodological setup of SEA and its practical implementation in REACH restriction dossiers.

Considering the overall goal of REACH restrictions, i.e. establishing effective risk management measures for industrial chemicals at a Community-wide level, an SEA should adopt a social welfare perspective. This requires impact assessment in SEAs to be comprehensive and comprehensible. Our analysis shows, however, that the current scope of SEA in restriction dossiers has been rather narrow. Specifically, quantitative assessments were performed predominantly for selected impact categories, in particular economic and health impacts, and evaluated a restriction option's effectiveness. Furthermore, the assessment of economic impacts focused on direct (financial) costs such as compliance and substitution costs. Similarly, the few dossiers quantifying avoided direct and indirect health damage costs relied on existing estimates of medical treatment costs, morbidity and mortality cost estimates available in the scientific and policy literature. Environmental, social, distributional and wider economic impacts were either evaluated qualitatively or remained unassessed.

There may be several reasons for the fragmentary assessment of impacts. First, existing evidence on the properties and risks of individual substances is often incomplete or inconclusive. Relevant in-house data of companies are usually confidential and not accessible for dossier submitters. This complicates developing a distinct list of, for example, health and environmental impacts, and prioritising impacts that are most relevant for the scope of a 


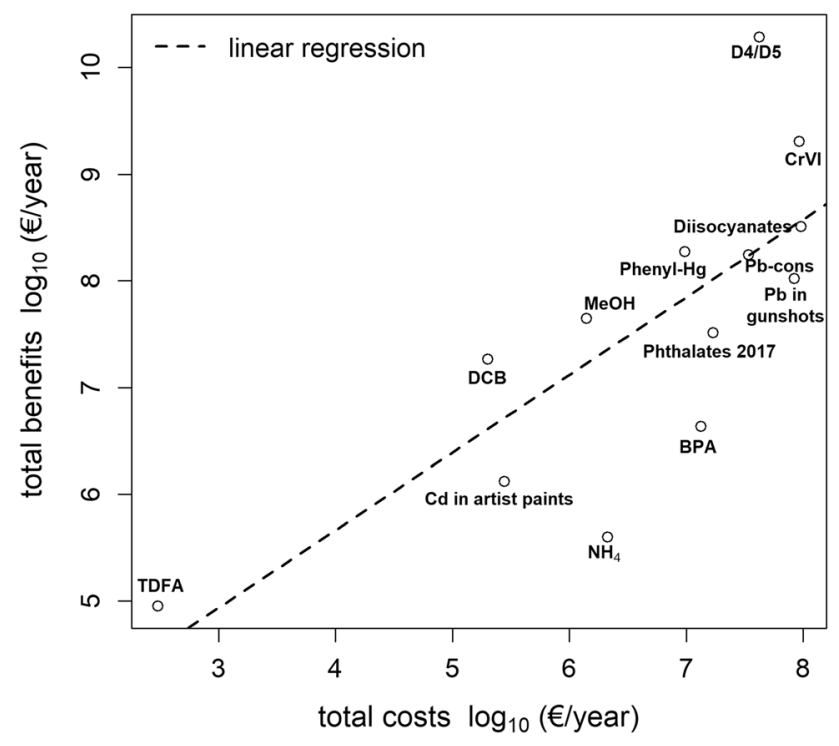

Fig. 5 Benefits versus cost estimates retrieved from 13 REACH restriction dossiers. Source ECHA (2019d), own calculations

restriction dossier. Second, for several impact categories (health, environmental, distributional impacts), there is a lack of monetary values that allow transforming impacts into benefit and cost estimates. Generating these values, for example by performing a restriction-tailored willingnessto-pay or remediation cost study, is time- and resourceconsuming and therefore not feasible within the time frame of a restriction procedure, and the personal endowment of regulatory agencies. Fourth, our review points to a fundamental lack of ready-for-use approaches for a concernbased impact assessment. For instance, while for some pollutants (e.g. metals, see Giang and Selin 2016; Nedellec and Rabl 2016; pesticides, see Fantke et al. 2012) health impact assessment approaches have been developed and applied, for most chemicals and endpoints the necessary methodological groundwork and the analytic routines for assessing environmental and health impacts are lacking (Gabbert 2017; Holland 2017a, b; Hunt and Dale 2018). Consequently, health and environmental impact assessment in REACH restriction dossiers largely remained at the level of standard environmental risk metrics, e.g. the expected change of the risk characterisation ratio, or estimates of avoided emissions as proxy of avoided environmental and health impacts. While emissions are an obvious starting point for assessing exposure and, thus, environmental and health impacts, they do not always adequately capture the regulatory concerns related to the chemicals addressed in REACH restriction processes. For example, several dossiers addressed chemicals which meet the criteria for being classified as PBT/vPvB (e.g. PFOA, D4/D5, decaBDE). As argued by Gabbert and Hilber (2016), these chemicals are stock pollutants, i.e. they can accumulate in the environment and, therefore, an unregulated release can cause long-term impacts to ecosystems and to human health. Hence, the relevant variable for assessing impacts is the stock-i.e. expected environmental concentrationsduring the release period and the period after regulatory measures have been adopted (see Gabbert et al. (2017) for a detailed discussion). Since the stock can remain in the environment even long after emissions have ceased, estimates of avoided annual emissions ignore long-term impacts and will likely overestimate expected benefits of a restriction. Consequently, cost-effectiveness ratios of restriction options based on emission estimates, and comparisons of such ratios across restriction options or dossiers are of little informational value and can even be misleading.

While most dossiers identified two or more restriction options, only few dossiers performed a comparative SEA. Interestingly, the preferred restriction option was not necessarily the one with the most favourable estimate of benefit-cost ratio, or with the lowest cost per unit of effect (e.g. per $\mathrm{kg}$ emission reduction). This implies that the selection of the preferred option was largely independent of the results of SEA.

\section{CONCLUSIONS}

Of the $24 \mathrm{REACH}$ restriction dossiers considered in this paper, 23 included an SEA. This underlines that SEA, though according to Article 68 of the REACH legislation (EC 2006) not being mandatory, is considered important for the evaluation of REACH restriction options, in particular of their effectiveness. However, despite the remarkable effort that dossier submitters have put in conducting an SEA, its current contribution in REACH restriction dossiers boils down to synthesising existing knowledge on selected impacts, benefits and costs.

Considering that, complementary to REACH authorisations, restriction procedures are a key regulatory instrument towards a safe use of chemicals in Europe and beyond (Coria 2018; Georgiou et al. 2018), the function of SEA as a decision-support tool could and should be strengthened. First, attention should be given to improving the quality of impact assessments in an SEA. In particular, there is an urgent need to developing integrated methods which allow for a concern-based evaluation of impacts. Such methods must link environmental assessments (toxicological hazard and risk assessment, environmental fate and distribution modelling, exposure assessments, environmental monitoring) with economic approaches addressing the assessment and valuation of impacts, and with tools that guide the aggregation and comparison of impacts. This requires substantial investments into research and capacity building. 
Second, the selection of the preferred restriction option should emerge from its relative superiority in relation to alternative RMOs. Thus, a comparative SEA, even if not being required by law, should become the default in order to improve the transparency and credibility of the restriction decision, and to increase the value of SEAs for regulatory decision-making.

Acknowledgements Dr. I. Hilber gratefully acknowledges financial support from the WIMEK Graduate School of Wageningen University \& Research.

Open Access This article is distributed under the terms of the Creative Commons Attribution 4.0 International License (http:// creativecommons.org/licenses/by/4.0/), which permits unrestricted use, distribution, and reproduction in any medium, provided you give appropriate credit to the original author(s) and the source, provide a link to the Creative Commons license, and indicate if changes were made.

\section{REFERENCES}

Béal, S., and M. Deschamps. 2016. On compensation schemes for data sharing within the European REACH legislation. European Journal of Law and Economics 41: 157-181.

Brouwer, R., J. Cauchi, and J. Verhoeven. 2016. Regulatory decisionmaking under uncertainty: Are costs proportionate to benefits when restricting dangerous chemicals on European markets? Regulatory Toxicology and Pharmacology 68: 438-446.

Coria, J. 2018. The economics of toxic substance control and the REACH directive. Review of Environmental Economics and Policy 12: 342-358.

Daston, G.P., J.C. Cook, and R.J. Kavlock. 2003. Uncertainties for endocrine disrupters: Our view on progress. Toxicological Sciences 74: 245-252.

ECHA. 2007. Guidance for the preparation of an Annex XV dossier for restrictions, guidance for the implementation of $\mathrm{REACH}$. ECHA, Helsinki. https://echa.europa.eu/documents/10162/230 36412/restriction_en.pdf/d48a00bf-cd8d-4575-8acc-c1bbe9f9c3f6. Accessed Apr 2019.

ECHA. 2008. Guidance on socio-economic analysis-Restrictions. Guidance for the implementation of REACH. ECHA, Helsinki. https://echa.europa.eu/guidance-documents/guidance-on-reach. Accessed Apr 2019.

ECHA. 2010. Addendum to the guidance on socio-economic analysis (SEA)-Restrictions. Calculation of compliance costs. ECHA, Helsinki. https://echa.europa.eu/documents/10162/13576/appen dix1-calculation_compliance_costs_case_restrictions_en.pdf/ 1080ccd2-a838-4e77-87a1-2cfe6673d377. . Accessed Apr 2019.

ECHA. 2011. Guidance on the preparation of socio-economic analysis as part of an application for authorisation. ECHA, Helsinki. https:// echa.europa.eu/documents/10162/23036412/sea_authorisation_en. pdf/aadf96ec-fbfa-4bc7-9740-a3f6ceb68e6e. Accessed Apr 2019.

ECHA. 2016. Cost and benefit assessments in the REACH restriction dossiers. ECHA-16-R-07-EN, ECHA, Helsinki. https://echa.europa. eu/documents/10162/13630/cost_benefit_assessment_en.pdf. Accessed Apr 2019.

ECHA. 2019a. Authorisation. ECHA, Helsinki. https://echa.europa.eu/ substances-of-very-high-concern-identification-explained. Accessed Apr 2019.
ECHA. 2019b. Restriction procedures. ECHA, Helsinki. https://echa. europa.eu/regulations/reach/restrictions/restriction-procedure. Accessed Apr 2019.

ECHA. 2019c. Adopted opinions on restriction proposals. ECHA, Helsinki. https://echa.europa.eu/previous-consultations-on-restri ction-proposals. Accessed Apr 2019.

ECHA. 2019d. Substances restricted under REACH. ECHA, Helsinki. https://www.echa.europa.eu/substances-restricted-under-reach. Accessed Apr 2019.

ECHA. 2019e. Restriction process. ECHA, Helsinki. https://echa. europa.eu/restriction-process. Accessed Oct 2019.

EU. 1976. Council Directive 76/769/EEC on the approximation of the laws, regulations and administrative provisions of the Member States relating to restrictions on the marketing and use of certain dangerous substances and preparations. Official Journal of the European Communities, Brussels. https://eur-lex.europa.eu/ legal-content/EN/TXT/?uri=CELEX:31976L0769. Accessed Apr 2019

European Commission. 2000. Directive 2000/60/EC of the European Parliament and the Council establishing a framework for the Community action in the field of water policy. http://ec.europa. eu/environment/water/water-framework/index_en.html. Accessed 9 June 2016.

European Commission. 2006. Regulation (EC) No. 1907/2006 of the European Parliament and of the Council of 18 December 2006 concerning the Registration, Evaluation, Authorisation and Restriction of Chemicals (REACH) [...]. Official Journal of the European Union, 30 Dec 2006, L396. https://eur-lex.europa. eu/legal-content/EN/TXT/?uri=CELEX:32006R1907. Accessed Apr 2019.

European Commission. 2019. Better regulation: Guidelines and toolbox. Chapter III: Better regulation guidelines-Impact assessment. https://ec.europa.eu/info/sites/info/files/better-regula tion-guidelines-impact-assessment.pdf. Accessed Apr 2019.

Fantke, P., R. Friedrich, and O. Jolliet. 2012. Health impact and damage cost assessment of pesticides in Europe. Environment International 49: 9-17.

Fleurbaey, M., and S. Zuber. 2013. Climate policies deserve a negative discount rate. Chicacgo Journal of International Law 13: $565-595$.

Gabbert, S. 2017. Economic assessment and valuations of environmental and health impacts caused by Perfluorooctanoic acid (PFOA) and its salts. OECD Environment Working Papers No. 128, OECD, Paris, https://www.oecd-ilibrary.org/docserver/f5250 745-en.pdf?expires $=1556275030 \&$ id $=i d \&$ accname $=$ guest\&checksu m=87197231F89571F5F9659D1BFCE03787. Accessed Apr 2018.

Gabbert, S., S. Hahn, M. Klein, M. Nendza, and F. Oosterhuis. 2017. Approach for evaluation of PBTs subject to authorisation and restriction procedures in context of socio-economic analysis. https://publications.europa.eu/en/publication-detail/-/publication/ff 4fea17-704d-11e8-9483-01aa75ed71a1/language-en/format-PDF/ source-71972846. Accessed Apr 2019.

Gabbert, S., and I. Hilber. 2016. Time matters: A stock-pollution approach to authorisation decision-making for $\mathrm{PBT} / \mathrm{vPvB}$ chemicals under REACH. Journal of Environmental Management 183: 236-244.

Getzner, M., and D. Schulz-Zak. 2018. Benefits and costs of regulating and restricting chemicals: The European Union's REACH system and its effects on the Austrian economy. Journal of Benefit Cost Analysis 9: 462-495.

Giang, A., and N.E. Selin. 2016. Benefits of mercury controls for the United States. PNAS 113: 286-291.

Georgiou, S., C. Rheinberger, and M. Vainio. 2018. Benefit-cost analysis in EU chemicals legislation: Experiences from over 100 REACH applications for authorisation. Journal of Benefit Cost Analysis 91: 181-204. 
Hansen, S.F., L. Carlsen, and J.A. Tickner. 2007. Chemicals regulation and precaution. Does REACH really incorporate the precautionary principle. Environmental Science \& Policy 10: 395-404.

Heal, G. 2007. Discounting: A review of basic economics. The University of Chicago Law Review 74: 59-77.

Hilber, I., and S. Gabbert. 2019. Choosing the best for preventing the worst: A structured analysis of the determinants for selecting risk management options in REACH restriction dossiers (in progress)

Holland, M. 2017a. Economic valuation in formaldehyde regulation. OECD Working Party on Integrating Environmental and Economic Policies, OECD, Paris, http://www.oecd.org/chemical safety/risk-management/sacame.htm. Accessed Apr 2019.

Holland, M. 2017b. Socio-economic assessment of phthalates. OECD Working Party on Integrating Environmental and Economic Policies, OECD, Paris, http://www.oecd.org/chemicalsafety/riskmanagement/sacame.htm. Accessed Apr 2019.

Hunt, A., and N. Dale. 2018. Economic valuation in 1-methyl-2-pyrollidone (NMP) regulation. OECD Working Papers ENV/WKP(20 18)5, OECD, Paris, https://www.oecd-ilibrary.org/docserver/ef67fa 08-en.pdf?expires $=1556268247 \&$ id=id\&accname=guest\&checksum $=$ C605DB63389A07A1DA1FA940C141DE5F. Accessed Apr 2018.

Klika, C. 2015. The implementation of the REACH authorisation procedure on chemical substances of concern: What kind of legitimacy? Politics and Governance 3: 128-138.

Nedellec, V., and A. Rabl. 2016. Costs of health damage from atmospheric emissions of toxic metals: Part 1-Methods and results. Risk Analysis 36: 2081-2095.

OECD. 2002. Technical guidance document on the use of socioeconomic analysis in chemical risk management decision making. OECD Environmental, Health and Safety Publications, Series on Risk Management, No. 14: ENV/JM/MONO(2002)10, OECD, Paris. http://www.oecd.org/officialdocuments/publicdis playdocumentpdf $/$ ?cote $=$ env $/ \mathrm{jm} / \mathrm{mono}(2002) 10 \&$ doclanguage $=$ en. Accessed Apr 2019.
Osborne, M. 2016. Exponential versus hyperbolic discounting: A theoretical analysis. https://papers.ssrn.com/sol3/papers.cfm?abs tract_id=2518162. Accessed Feb 2019.

Reihlen, A., and D. Lüskow. 2007. Analysis of studies discussing benefits of REACH. Ökopol, February 2007. https://ec.europa. eu/environment/chemicals/reach/pdf/background/reach_benefit_ studies.pdf. Accessed Sept 2019.

Samuelson, P.A. 1937. A note on the measuring utility. The Review of Economic Studies 4: 155-161.

Weitzman, M.L. 1998. Why the far-distant future should be discounted at its lowest possible rate. Journal of Environmental Economics and Management 36: 201-208.

Publisher's Note Springer Nature remains neutral with regard to jurisdictional claims in published maps and institutional affiliations.

\section{AUTHOR BIOGRAPHIES}

Silke Gabbert $(\bowtie)$ is an Associate Professor at Wageningen University (The Netherlands). Her research interests are the economics of chemicals risk management and regulation.

Address: Department of Social Sciences, Environmental Economics and Natural Resources Group, Wageningen University \& Research, Hollandseweg 1, 6700 EW Wageningen, The Netherlands.

e-mail: silke.gabbert@wur.nl

Isabel Hilber is a research associate at the research group of Environmental Analytics, Agroscope (Switzerland). Her research interests include the assessment of bioavailability of organic contaminants that are PBT in environmental matrices such as soil, biochar, plants and ruminant husbandry animals.

Address: Agroscope, Reckenholzstrasse 191, 8046 Zurich, Switzerland. 